\title{
EXPERIMENTAL EVALUATION OF TUBE SUPPORT PLATE CREVICE CHEMISTRY
}

\author{
Allen Baum
}

\section{NOTICE}

This report was prepared as an account of work sponsored by an agency of the United States Government. Neither the United States Government nor any agency thereof, nor any of their employees, nor any of their contractors, subcontractors or their employees, makes any warranty, express or implied, or assumes any legal liability or responsibility for the accuracy, completeness, or any third party's use or the results of such use of any information, apparatus, product, or process disclosed, or represents that its use would not infringe privately owned rights. Reference herein to any specific commercial product, process, or service by trade name, trademark, manufacturer, or otherwise, does not necessarily constitute or imply its endorsement, recommendation, or favoring by the United States Government or any agency thereof or its contractors or subcontractors. The views and opinions of authors expressed herein do not necessarily state or reflect those of the United States Government or any agency thereof. 


\title{
EXPERIMENTAL EVALUATION OF TUBE SUPPORT PLATE CREVICE CHEMISTRY
}

\author{
Allen Baum \\ Bechtel Bettis, Inc. \\ PO Box 79 \\ West Mifflin, PA, 15122
}

\begin{abstract}
A test methodology for measuring temperature, impedance, $\mathrm{pH}$, and electrochemical potential distributions within a sludge-packed tube support plate crevice in a laboratory test is described. The method successfully showed that there were large concentration gradients between the tube and tube support plate sides of the crevice. The testing also showed that strong bases concentrated more effectively than strong acids, and that the crevice $\mathrm{pH}$, when exposed to seawater-based solutions, increased with increasing superheat and decreasing bulk concentration. The large variations in the crevice chemistry observed under heat transfer were eliminated upon shutdown. These new test data suggest that it might be beneficial to evaluate the variation in the extent of stress corrosion cracking with tube support plate elevation found in some steam generators in light of local chemistry changes, as well as the variation in tubing temperature. Because of the large crevice chemistry gradients during boiling heat transfer and their subsequent homogenization upon test shutdown, the results suggest reassessing the use of hideout return measurements and tube deposit analyses in industry to infer the crevice chemistry under heat transfer conditions.
\end{abstract}

\section{Introduction}

There are numerous hypotheses regarding the cause of OD-initiated stress corrosion cracking (ODSCC) in recirculating steam generators. Causative mechanisms based upon solid, ${ }^{1}$ liquid, ${ }^{2}$ and gaseous ${ }^{3}$ environments, as well as in acidic, alkaline, and neutral chemistries, ${ }^{4}$ have been proposed. One reason for the lack of consensus is that it is difficult to infer the chemistry at the tube surface, either experimentally or analytically. As an example of this uncertainty, the $\mathrm{pH}$ range calculated by the MULTEQ computer code for the concentration of dilute seawater plus silica is presented in Figure 1, assuming alternate steam transport models. The "steam retained" option effectively limits the concentration factor of volatile species to the reciprocal of the partition coefficient, while the "steam removed" option allows unlimited concentration. ${ }^{5}$ As the difference between the tube temperature and the secondary saturation temperature increases, the $\mathrm{pH}$ can vary between approximately 2.5 and 7.5 , depending upon the model assumed. The purpose of this paper is to qualitatively characterize the solutions forming at the tube surface within tube support plate crevices, and thereby reduce the uncertainty in the $\mathrm{pH}$ calculation shown in Figure 1.

\section{Literature Review}

There have been several experimental efforts to characterize the crevice chemistry under heat transfer conditions. Hermer et $\mathrm{al}^{6}$ inserted a reference electrode radially through a tube support ring to determine the effect of boric acid addition on the local electrochemical potential (ECP) within a packed crevice. Lumsden and co-workers ${ }^{7}$ have used a similar approach to characterize the temperature distribution and ECP in a simulated tube support plate crevice, primarily by concentrating sodium hydroxide. Balakrishnan ${ }^{8}$ has measured the $\mathrm{pH}$ and the ECP in an enlarged tube support plate crevice with combinations of sodium, chloride, and sulfate addition. While the probes in the Reference 1 and 2 works were inserted radially through the tube support plate, the probes in the Reference 3 work were inserted axially into the crevice. Reference 1 used a primary circulating loop to provide heat input to the crevice, while References 2 and 3 used a cartridge heater in a static autoclave. D. You et al ${ }^{9}$ measured the composition of concentrated solutions by slowly flashing the autoclave contents while injecting dilute solution to maintain a constant volume. Although the testing was performed isothermally, the concentrates produced may resemble those found in steam generator crevices. The study described here differs from the other work in the focus on radial and axial variations within a tube support plate crevice, in utilizing crevice $\mathrm{pH}$ and impedance measurements as well as ECP measurements, and considering a broader range of solution chemistries. 


\section{Experimental}

A schematic of the instrumented test piece is presented in Figure 2. The crevice was contained within a cylindrical hole tube support plate crevice that had been prepacked with magnetite. Porous sinters were placed at each end of the crevice to contain the magnetite. Multiprobes for measuring the local temperature, the $\mathrm{pH}$, the impedance, and the platinum and Alloy 600 potentials were placed in axial grooves at different axial and circumferential locations on both the tube and support plate sides of the crevice. The multiprobes were mounted axially so that they were perpendicular, rather than parallel, to the temperature gradient between the tube and the support plate. The multiprobes were located in slots machined into the tube and support plate surfaces so as to not obstruct the crevice and to represent the thermal and chemical environment at the tube and tube support plate surfaces as closely as possible.

The instrumented crevice contained seven multiprobes on the tube side and four multiprobes on the tube support plate side of the crevice. The tube also contained four embedded thermocouples to permit comparisons to the multiprobe temperature measurements. In order to limit the tube surface area containing grooves for the multiprobes and slots for the embedded thermocouples to less than $25 \%$ of the tube surface area within the crevice, it was necessary to utilize a tube having a 2.54-cm (1") OD. The crevice radial gap was increased to $0.64 \mathrm{~mm}$ (25 mils) so that the gap width would be comparable to the OD of the multiprobes. The crevice length was $3.18 \mathrm{~cm}\left(1 \frac{1 / 4 ")}{}\right)$ A microsample line was mounted radially through the support plate at the axial midpoint.

In addition to the instrumented crevice, the test contained multiprobes and embedded thermocouples located on the tubing free-span, as well as multiprobes, two silver-silver chloride reference electrodes, and a tungsten wire electrode located in the bulk fluid. The crevice instrumentation was referenced to both the reference electrodes and the tungsten wire electrode. However, as testing progressed, the reference electrode readings became more variable, so that the tungsten wire electrode became the primary reference. Since most tests were conducted with little variation in the bulk chemistry, the potentials should not have been affected by variations in the reference electrode.

The test utilized a forced-flow heating fluid and a natural circulation steam-side system. Chemistry control was maintained by continuous feed and bleed. In order to preclude softening of the multiprobe insulating material, the primary temperature was limited to $285^{\circ} \mathrm{C}\left(545^{\circ} \mathrm{F}\right)$. Testing was conducted by maintaining a $238^{\circ} \mathrm{C}\left(460^{\circ} \mathrm{F}\right)$ saturation temperature and progressively increasing the heating fluid temperature, achieving temperature differences (superheats) of $11,22,36$, and $47^{\circ} \mathrm{C}\left(20,40,65\right.$, and $\left.85^{\circ} \mathrm{F}\right)$.

Testing was performed in AVT chemistry, as well as with additions of sodium chloride, sodium hydroxide, ammonium sulfate, ammonium chloride, and seawater. The species were selected to represent a range of possible acid, neutral, and alkaline forming crevice chemistries. Autoclave concentrations were typically in the several hundred to low thousand-ppb range, well below those used in other crevice chemistry evaluations using cartridge heat input. ${ }^{2,3}$ Some test segments were also performed in which the feed was suddenly changed to a second makeup tank having a very different chemistry from the first, while all other test conditions were held constant. These segments were intended to represent various possible chemistry upsets, and afforded the opportunity to monitor the crevice when only the feed chemistry changed.

\section{Thermal-Hydraulic Characterization}

The initial AVT testing was conducted, in part, to verify that the groove-mounted multiprobes represented the environment at the tube surface. Figure 3 compares the readings of embedded and multiprobe thermocouples located at the crevice axial midpoint. As indicated, with the exception of the test at $11^{\circ} \mathrm{C}$ superheat, the microprobe thermocouple readings are only slightly below the embedded thermocouple readings. Since the embedded thermocouples are located a few mils below the tubing surface, the readings should be somewhat above the tube surface temperature. Consequently, the small difference between the two sets of results suggests that the slotmounted multiprobes should approximate the tube surface environment at superheats above $11^{\circ} \mathrm{C}$. The response of multiprobe thermocouples mounted on the tube support plate (TSP) side of the crevice is also plotted in Figure 3. While the tube-side thermocouples have superheats that approach the primary temperature, the TSP-side thermocouples have superheats that are close to the secondary saturation temperature, indicating that there is a large radial temperature gradient across the crevice. Note that the temperature readings have been normalized to the difference between the primary and secondary temperatures. This normalization facilitates inferring the heat transfer regime at low superheats, when all temperatures approach each other. 
The axial variation in the relative superheat distribution is presented in Figure 4. All probes, other than probe 1, show a sudden increase in relative superheat, indicative of dryout, as the primary superheat was increased from 10 to $24^{\circ} \mathrm{C}\left(18\right.$ to $\left.43^{\circ} \mathrm{F}\right)$. The reduction in relative superheat evident on most probes produced by increasing the superheat from 8 to $10^{\circ} \mathrm{C}\left(14\right.$ to $\left.18^{\circ} \mathrm{F}\right)$ reflects the improvement in heat transfer with increasing heat flux typically associated with nucleate boiling heat transfer.

The response of multiprobe thermocouples located on opposite sides of the crevice during AVT testing and with solute addition is compared in Figure 5. Consistent with a gradual replacement of superheated steam by a concentrated liquid film, the tube superheats decreased while the TSP superheats increased with solute addition. The largest changes were found for the test segment using the highest seawater concentration. In addition to a relatively high solute accumulation rate, precipitation of less soluble seawater salts may have increased the thermal conductance. Nevertheless, solute addition in this test affected local temperatures to a far lesser degree and with greater predictability than in tests having cartridge heat input. ${ }^{2}$

\section{Crevice Chemistry Characterization}

Solute Effects on Crevice $\mathrm{pH}$ and Impedance Distributions. Figure 6 presents contour maps in the r-z plane of the electrochemical impedance distribution within the instrumented crevice at various times during the addition of $300-\mathrm{ppb}$ chloride as seawater. The values represent the impedance modulus at a $1000 \mathrm{~Hz}$ frequency. This frequency was found to be the best compromise for measuring solution conductivity without being overwhelmed by either corrosion processes or capacitive shunting. The contours were inferred from the probe readings at discrete points on the tube and tube support plate sides of the crevice. As such, the contours should only be considered approximate. Decreasing impedance values reflect a combination of an increased solute concentration and an increased solute film thickness between adjacent electrodes. As indicated by the maps, the impedance readings steadily decreased on the tube side of the crevice as the test progressed, while there was essentially no change in the readings on the TSP-side of the crevice. These results suggest that the strong temperature gradient evident across the crevice shown in Figure 3 results in chemical concentration preferentially occurring on the tube side of the crevice. The results also highlight the importance of locating probes directly on the tube surface. A separation of even $0.1 \mathrm{~mm}$ would likely have produced very different results.

Map A shows the impedance distribution at the start of testing. The darkened region at one end of the crevice indicates that some residual solute was present from the previous test. While it may have been preferable to start the test with a uniformly solute-free crevice, the residual reflects the difficulties inherent in attempting to remove solutes by conventional hot and cold soaking procedures. Maps $\mathrm{B}$ and $\mathrm{C}$ show that concentration occurs preferentially in crevice regions found to experience dryout conditions at 10 and $24^{\circ} \mathrm{C}$, respectively, in Figure 4.

The effect of several chemistry changes on the impedance distribution at the crevice midpoint is presented in Figure 7. The feed chemistry was changed from AVT to ammonium chloride (at two concentrations), to sodium hydroxide, and then back to AVT, all at a constant $36^{\circ} \mathrm{C}\left(65^{\circ} \mathrm{F}\right)$ superheat. The relative sodium and chloride hideout rates, defined as the difference between the feed and autoclave concentrations divided by the feed concentration, are also shown in the figure. As indicated, AVT chemistry and ammonium chloride injection, even at a relatively high concentration, had little effect on the impedance measurements. It is interesting to note that ammonium chloride injection did not affect the impedance, even though approximately $18 \%$ of the injected chloride hid out in the crevice. Adding sodium hydroxide (at a 1:3 molar ratio relative to chloride) caused an almost instantaneous impedance reduction on the tube side of the crevice, while having essentially no impact on the TSP side. Sodium hydroxide addition increased the chloride hideout rate by $50 \%$, although the rate remained below the sodium hideout rate. The impedance reduction and the increased hideout rates are indicative of forming a concentrated sodium chloride solution at the tube surface. While switching back to AVT chemistry had little effect on the impedance distribution, shutting the test down produced large variations in the TSP-side impedance, with values ultimately approaching those on the tube side. Shutdown of other test segments invariably produced the same result; that is, while there were substantial spatial variations within the crevice when operating with an applied superheat, these variations were eliminated immediately following shutdown.

The results presented in Figure 8 may provide an explanation for why acid chlorides hid out within the instrumented crevice but did not affect the impedance measurements. The figure shows the effect of switching from sodium 
chloride to sodium hydroxide addition on the potential of tungsten electrodes referenced to the tungsten wire placed in the bulk autoclave fluid. Since the ECP of a tungsten electrode is relatively insensitive to oxidizing or reducing conditions, it provides a measure of changes in the $\mathrm{pH}$. An increasing potential is indicative of an acidic environment. As would be expected, sodium chloride addition did not affect the potential measurements on either side of the crevice. Two days after switching to sodium hydroxide addition, the tungsten potential on the tube side of the crevice rapidly decreased, indicative of an alkaline forming chemistry, as would be intuitively expected. However, the tungsten probe potential on the TSP side indicated an acidic environment, coincident with initiating sodium hydroxide addition, a most surprising observation. A similar trend was noted on all other TSP-side probes following sodium hydroxide addition. A possible explanation for this unusual distribution is that the chloride ions had been adsorbed by the crevice magnetite in previous testing, consistent with the observed hideout in the absence of an impedance response noted in Figure 7. An ion exchange mechanism, perhaps with hydroxyl ions, caused the chloride ions to be released, and their subsequent accumulation on the TSP side of the crevice.

Effect of Seawater Addition on Crevice $\mathrm{pH}$ Distribution. The variation in the tungsten potential with increasing superheat for three seawater concentrations is presented in Figure 9. The results for the two higher concentrations followed a characteristic pattern: there was a sudden decrease in the tungsten potential (or increase in the $\mathrm{pH}$ ) immediately following a step increase in superheat, followed by a gradual potential increase. The return to the original chemistry was faster and more complete for the test with 2700-ppb chloride than for 900-ppb chloride. Upon increasing the superheat from 22 to $36^{\circ} \mathrm{C}\left(40\right.$ to $\left.65^{\circ} \mathrm{F}\right)$, there was a sudden decrease but no subsequent potential increase. A similar trend may have been also present during the test at the lowest concentration, but it is more difficult to discern.

These results suggest that seawater ingress produced an acidic environment at the tube surface at lower superheats, at least at relatively high bulk concentrations, but that this environment became more difficult to sustain at higher superheats. The elevated boiling or evaporation rates attendant with an increased superheat evidently volatilized the excess chloride present in the liquid films, but some of the chloride inventory was restored with ongoing testing. The observed variations with concentration and superheat suggest that the equilibrium chemistry on the tube side of the crevice is governed by a balance between the chloride volatilization and evaporation rates, with lower superheats and higher bulk concentrations favoring an acidic environment.

A similar trend is also evident from the tungsten potentials measured following the shutdown of the three seawater addition test segments, presented in Figure 10. Because of the homogenization of the crevice chemistry, the results reflect the average crevice chemistry rather than a local variation. The results show that even following operation with a $36^{\circ} \mathrm{C}$ superheat, there was still net acidity in the crevice at the completion of the 2700 - and 900-ppb chloride addition tests, but that some alkalinity was present following the 300-ppb chloride addition test. The trend of increasing alkalinity with decreasing concentration may be a consequence of a surface-active volatilization process. That is, the concentrated liquid film surface area to thickness (or volume) ratio increases with decreasing bulk concentration. It is also interesting to note that the crevice $\mathrm{pH}$ converged to approximately the same acidic value following the first few hours of shut down. It is surmised that by this time, the crevice chemistry was dominated by the return of anions that had reacted with the crevice magnetite, rather than by residual crevice solutes.

Concentration of Strong Acids and Strong Bases. The impedance and $\mathrm{pH}$ response of selected probes during ammonium sulfate and sodium hydroxide addition are presented in Figures 11 and 12. The results in Figure 11 represent the only significant $\mathrm{pH}$ excursion identified on any probe during the strong acid addition testing (with either ammonium chloride or ammonium sulfate). The initial impedance is noted to be quite high, and perhaps surprisingly, increased slightly as testing progressed. Evidently, the $\mathrm{pH}$ excursion occurred in the absence of significant solute accumulation. This pattern is contrasted to the results in Figure 12, which are fairly representative of the probe response to sodium hydroxide addition. Unlike the Figure 11 results, the impedance decreased as the $\mathrm{pH}$ increased, consistent with solute accumulation on the tube surface. These differences highlight the importance of volatilization and magnetite interaction processes in limiting the capability of promoting highly acidic environments at the tube surface, particularly at elevated superheats.

\section{Comparisons to Industry Experience}

There are several possible analogies between these test results and industry steam generator operational experience. Examinations of tube support plate crevice assemblies removed from the Dampierre 1 and Ringhals 3 steam 
generators found that there was considerable radial variation in physical and chemical characteristics of the crevice deposits. ${ }^{10,11}$ The deposits on the tube side of the crevice were enriched in calcium, magnesium, phosphate, and silicate, while the deposits on the tube support plate side of the crevice were composed of almost $100 \%$ dense magnetite. Highly porous magnetite separated the two regions. Since the crevice gap widths were considerably higher than design values, the high-density magnetite layer evidently formed from corrosion of the carbon steel support plate rather than from externally deposited magnetite, similar to a denting corrosion process. These deposit morphology variations are consistent with the chemistry variations between the tube and TSP sides of the crevice reported here (as in Figure 8).

Evaluations of the axial variation of tube support plate eddy current indications have found that the temperature variation is much stronger than that deduced from isothermal laboratory tests. ${ }^{12}$ For instance, the equivalent activation energy for the variation in the fraction of tubes having stress corrosion cracking (SCC) indications at successive support plates in the steam generators of five plants was found to vary between 110 and $346 \mathrm{kcal} / \mathrm{mole}$. In comparison, isothermal laboratory tests in both primary and secondary side environments typically find the activation energy to be on the order of $40 \mathrm{kcal} / \mathrm{mole} .{ }^{13}$ This trend suggests that much of the support plate to support plate variation in the extent of ODSCC may be due to a mechanism other than a direct temperature effect.

The axial ODSCC variation in the five plants reported in Reference 12 has been plotted as a function of the primary superheat in Figure 13. Much of the variation is noted to occur over the 20 to $35^{\circ} \mathrm{C}$ range. This range is almost identical to the range over which net acidity was lost on the tube side of the crevice in the seawater addition tests (Figure 9). It can be conjectured that the large difference between the plant experience and the isothermal laboratory test results is due to variations in the tube-side chemistry with increasing superheat.

Figure 1 showed there is a large uncertainty band for the MULTEQ-calculated $\mathrm{pH}$ for concentrating seawater. While this testing did not quantitatively establish the local $\mathrm{pH}$ variation, the results of the seawater testing can be used to infer trends in the expected $\mathrm{pH}$, and thereby reduce the uncertainty. These trends are shown schematically in Figure 14. The testing suggests that the $\mathrm{pH}$ is acidic at low superheats but then becomes neutral to slightly alkaline at high superheats. Presumed variations with concentration, temperature, and crevice porosity are also shown. The results in Figure 10 suggest that the alkalinity likely increases as bulk concentrations are reduced to typical steam generator values. Although not explicitly evaluated, increasing anion volatility with increasing temperatures should cause the $\mathrm{pH}$ to become more alkaline as steam generator temperatures are approached. Finally, since the porosity ( $\varepsilon$ in Figure 14) of the prepacked crevice magnetite was lower than found in the plant crevices, it is possible that volatiles could escape from the crevice more readily in the test than in steam generators, leading to a more acidic condition in the steam generator. Nevertheless, the net effect of these uncertainties would likely lead to more alkaline conditions in steam generator crevices than are indicated by the test.

\section{Summary and Conclusions}

The testing found that crevice concentration processes are highly localized. Concentration preferentially occurred on the tube side of the crevice, with substantial $\mathrm{pH}$ and impedance gradients being maintained radially across the crevice. Shutting the test down essentially eliminated all of the variation present while operating with an applied superheat. Strong bases concentrated more effectively than strong acids, with acid concentration being limited both by volatility considerations and magnetite-solute interactions. Concentration of seawater, which may be a surrogate for other salt-based chemistries, produced a more complex distribution, with acidity levels decreasing with increasing superheat and decreasing bulk concentrations.

The variation in tube-side $\mathrm{pH}$ with increasing superheat found in the seawater addition testing may provide some insight to the strong variation in the extent of steam generator ODSCC found with support plate elevation. The results suggest that crevice acids may be volatilized at the highest superheat locations. The variations with radial location and applied superheat identified by the testing suggest that the steam generator shutdown hideout return chemistry, nominally representing a homogenization of the entire crevice solute inventory, may not be representative of the chemistry responsible for the observed corrosion. The strong radial variations found in the testing may assist in the interpretation of crevice morphology variations found in steam generator crevice assemblies. Finally, the changes in the crevice chemistry attendant with shutdown may introduce uncertainties in using pulled tube analyses to infer the chemistry present during plant operation. 


\section{References}

${ }^{1}$ B. Sala et al, "The Role of Silica Compounds in the Corrosion Process of the Secondary Side of Steam Generators: An Electrochemical Study," Proc. Eighth International Symposium on Environmental Degradation of Materials in Nuclear Power Systems - Water Reactors (La Grange Park, IL: American Nuclear Society, 1997).

${ }^{2}$ A. J. Baum, et al, "Development of Improved PWR Water Secondary Chemistry Guidelines," Proc. Eighth International Symposium on Environmental Degradation of Materials in Nuclear Power Systems - Water Reactors (La Grange Park, IL: American Nuclear Society, 1997).

${ }^{3}$ P. M. Scott and P. Combrade, "On the Mechanisms of Secondary Side PWR Steam Generator Tube Cracking," Proc. Eighth International Symposium on Environmental Degradation of Materials in Nuclear Power Systems Water Reactors (La Grange Park, IL: American Nuclear Society, 1997).

${ }^{4}$ P. Andresen et al, SCC in Acidic, Neutral, and Alkaline Environments, (Houston, TX: National Association of Corrosion Engineers, 1996).

${ }^{5}$ P. J. Millett and J. P. Paine, "Improvements in the Modeling of Crevice Chemistry in PWR Steam Generators Using the MULTEQ Code," EPRI TR-102706, August 1993.

${ }^{6}$ R. Hermer et al, "The Effect of Boric Acid on Alloy 600 Electrochemical Potentials in Steam Generator Crevice Environments," JAIF Int. Conference on Water Chemistry in Nuclear Power Plants, vol. 2, 1988, pp. 474-479.

${ }^{7}$ J. B. Lumsden et at, "Hideout in Prototypic Tube/Tube Support Plate Heated Crevices," Proc. Eighth International Symposium on Environmental Degradation of Materials in Nuclear Power Systems - Water Reactors (La Grange Park, IL:, American Nuclear Society, 1997).

${ }^{8}$ P. V. Balakrishnan, "Hideout, Hideout Return and Crevice Chemistry in Steam Generators," $13^{\text {th }}$ International Conference on the Properties of Steam, Toronto, Sept. 12-16, 1999, pp. 858-865.

${ }^{9}$ D. You, S. Lefèvre, and D. Féron, "A Chemical Study of Concentration Processes in Steam Generator Crevices: Influence of Boron on the Hideout of Sodium, Aluminum, and Silicon," Water Chemistry '98, Kashiwasaki, Japan, Oct. 1998, pp.443-448.

${ }^{10}$ L. Albertin et al, "Characterization of Deposits in Dampierre-1 Steam Generator Support Plate Crevices," Proc. Seventh International Symposium on Environmental Degradation of Materials in Nuclear Power Systems - Water Reactors, (Houston, TX: National Association of Corrosion Engineers, 1995).

${ }^{11}$ A. M. Lancha, et al, "Characterization of Ringhals 3 TSP Crevice and Tube Deposits," Proc. Eighth International Symposium on Environmental Degradation of Materials in Nuclear Power Systems - Water Reactors (La Grange Park, IL: American Nuclear Society, 1997).

${ }^{12}$ A. Baum, "Relationships Between Stress Corrosion Cracking Tests and Utility Operating Experience," Proc. Ninth International Symposium on Environmental Degradation of Materials in Nuclear Power Systems - Water Reactors (Warrendale, PA: TMS, 1999).

${ }^{13}$ R. J. Jacko, "Corrosion Evaluation of Thermally Treated Alloy 600 Tubing Primary and Faulted Secondary Water Environments," Electric Power Research Institute, EPRI NP-6721-SD, June 1980.

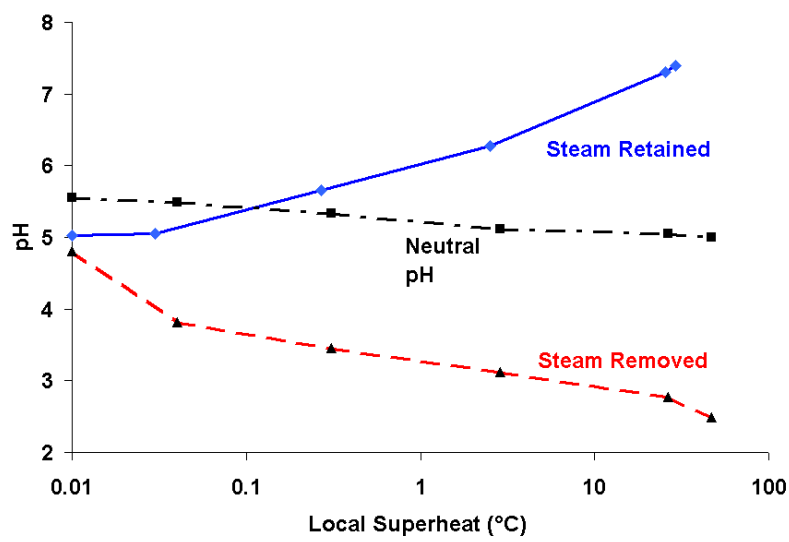

Figure 1. Effect of Steam Removal Assumption on MULTEQ-Calculated $\mathrm{pH}$ for Seawater Plus 35-ppb Silica

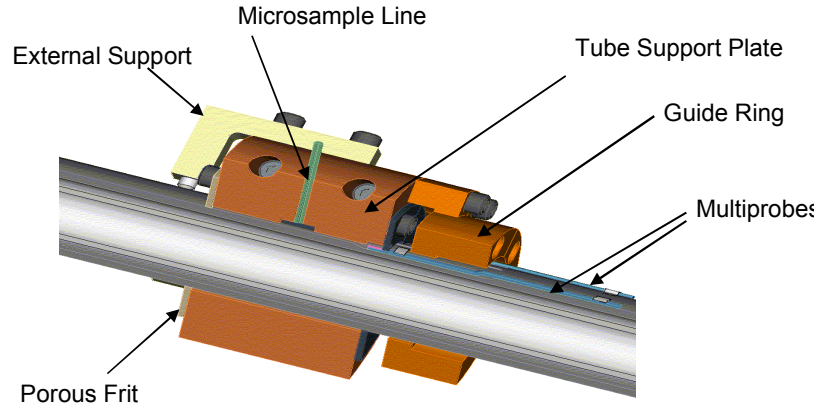

Figure 2. Test Piece Schematic 


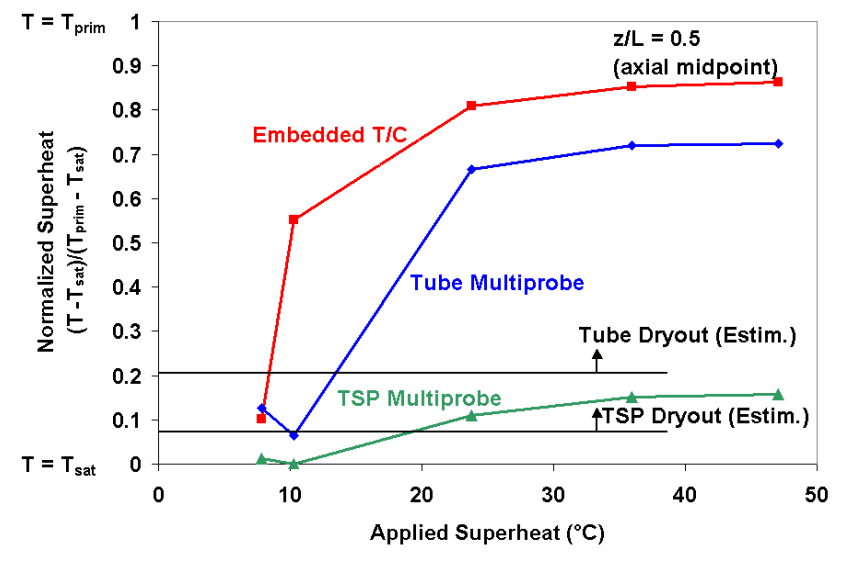

Figure 3. Comparison of Multiprobe and Embedded Thermocouple Response to AVT Chemistry

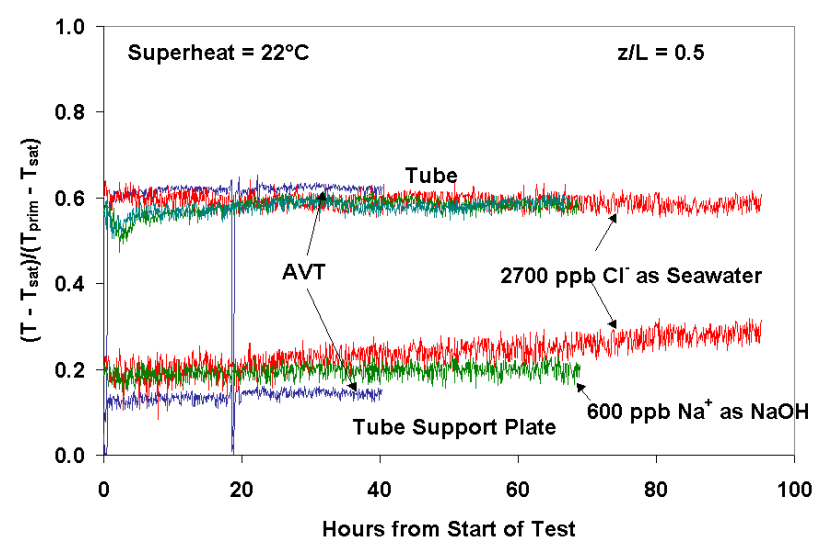

Figure 5. Effect of Chemical Addition on Relative Superheats

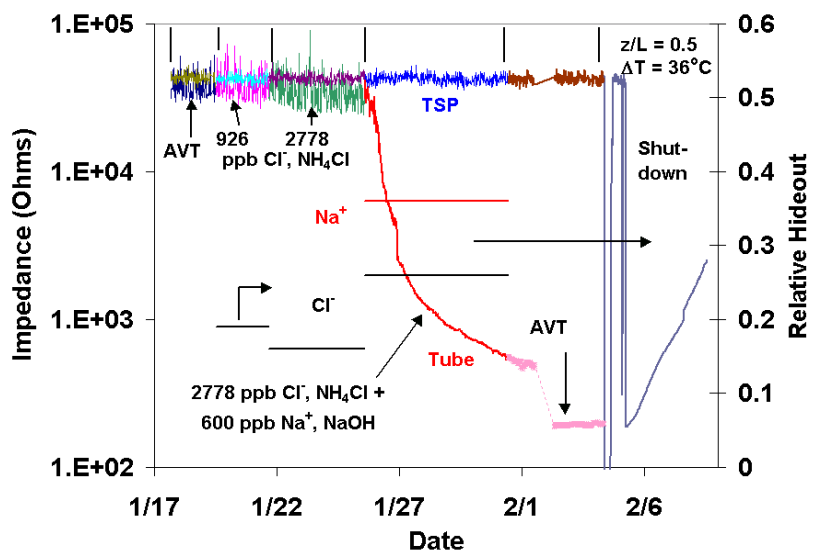

Figure 7. Effect of Chemistry Changes on Crevice Impedance Distribution

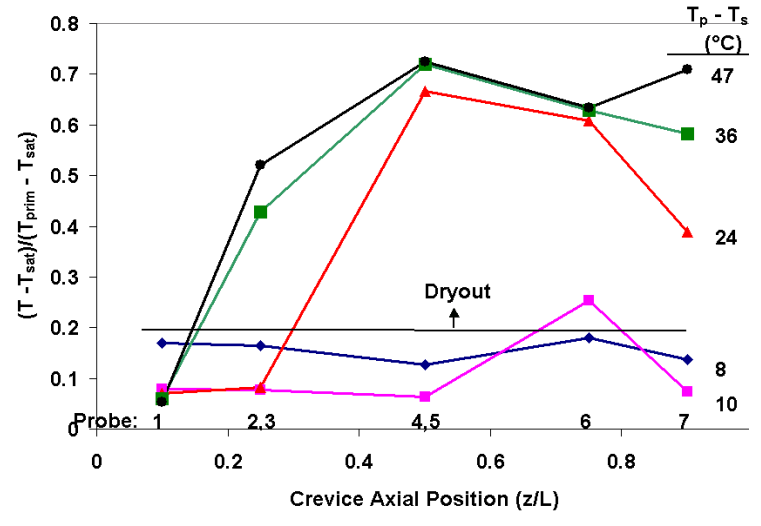

Figure 4 Variation in Relative Superheat with Axial Position for Various Applied Superheats

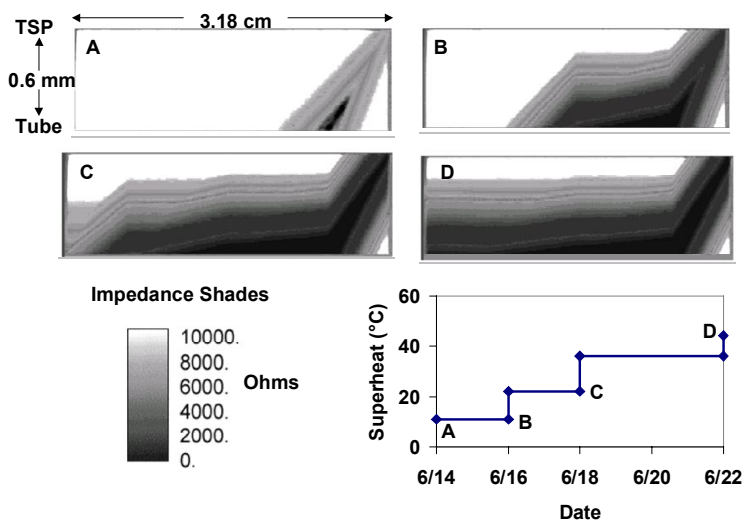

Figure 6. Effect of 300-ppb Cl- as Seawater on the Crevice Impedance Distribution

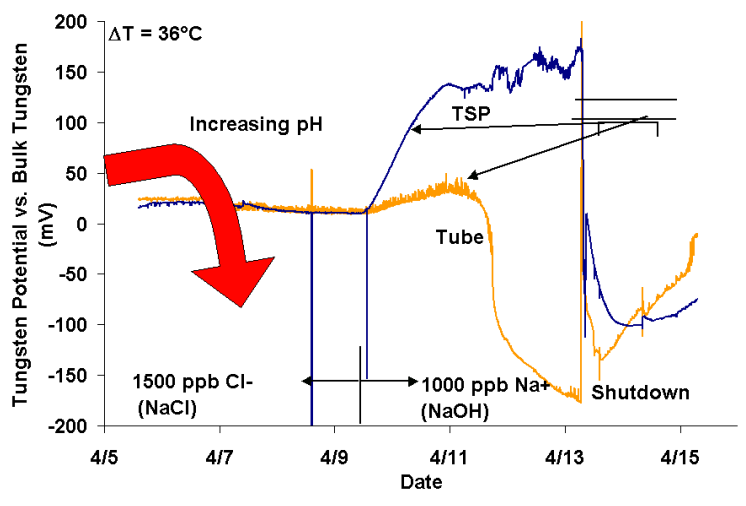

Figure 8. Effect of Switch to $\mathrm{NaOH}$ Addition on Radial pH Distribution 


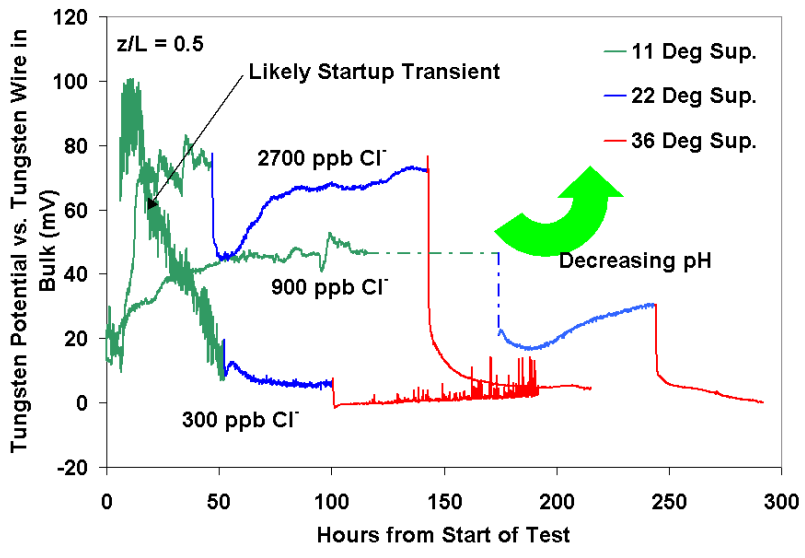

Figure 9. Tungsten Potential Variation in Seawater Addition Testing

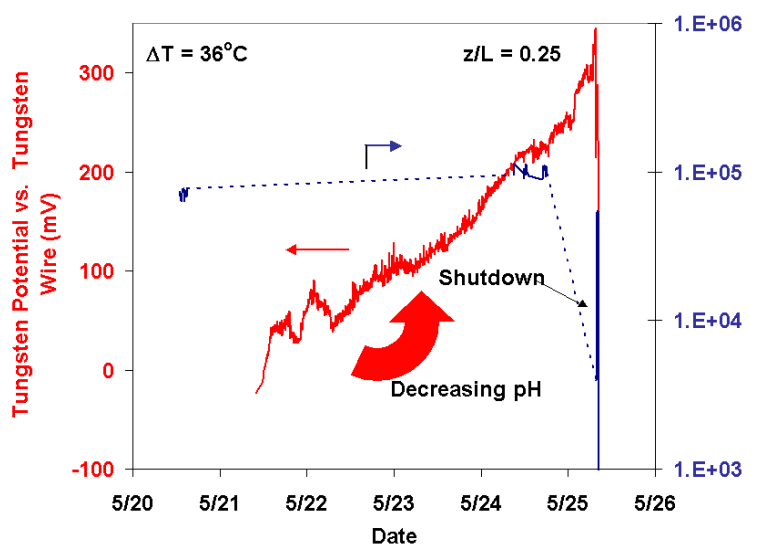

Figure 11. Response of Probe 2 During Addition of 1250-ppb Sulfate as Ammonium Sulfate

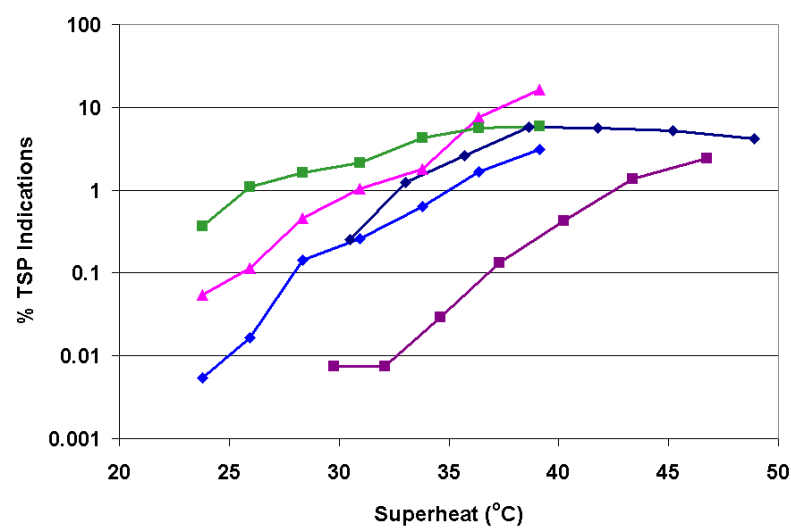

Figure 13. Variation in Plant ODSCC with Applied Superheat

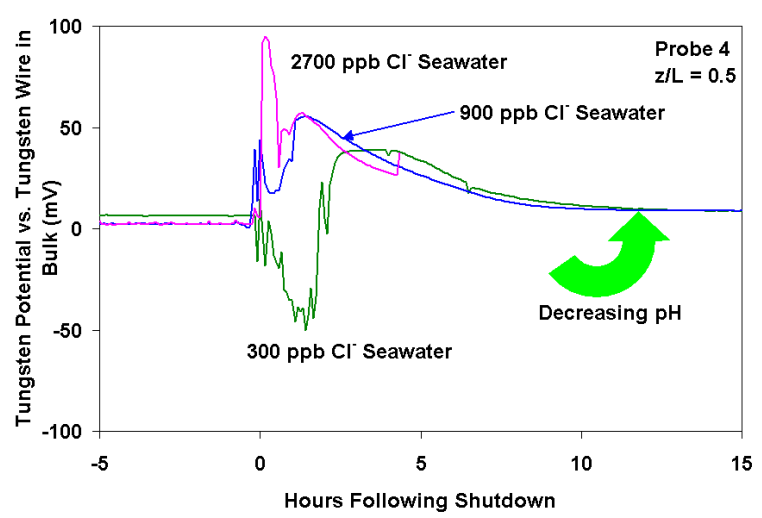

Figure 10. Tungsten Potential Variation Following Shutdown of the Seawater Addition Test Segments

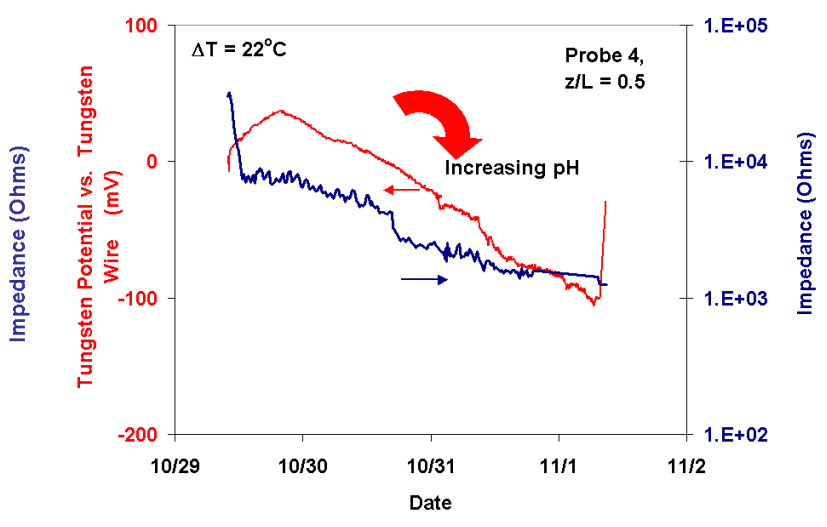

Figure 12. Response of Probe 4 during Addition of 600-ppb Sodium as Sodium Hydroxide

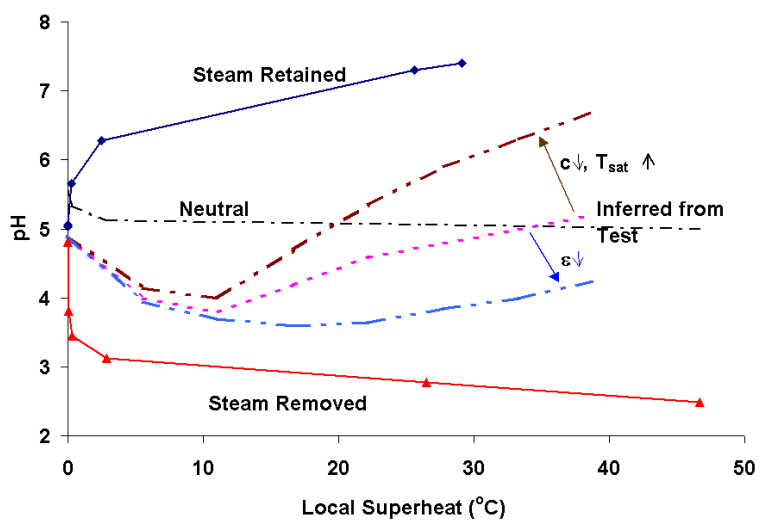

Figure 14. Inferred $\mathrm{pH}$ Variation of Seawater with Increasing Superheat 